\title{
Behavior Characteristics of Bonded Type Anchorage for CFRP Tendon
}

\author{
Jong Sup Park, Woo Tai Jung, Jae Yoon Kang, Moon Seoung Kum \\ Structural Engineering Research Division, Korea Institute of Construction Technology, Goyang, Korea \\ Email: jspark1@kict.re.kr, woody@kict.re.kr, jykang@kict.re.kr, moonseoung@kict.re.kr \\ Received September 10, 2013; revised October 10, 2013; accepted October 17, 2013
}

Copyright (C) 2013 Jong Sup Park et al. This is an open access article distributed under the Creative Commons Attribution License, which permits unrestricted use, distribution, and reproduction in any medium, provided the original work is properly cited.

\begin{abstract}
This paper examines the shear stress and displacement occurring in CFRP tendons through finite element analysis on the parameters influencing the anchoring performance to evaluate the behavioral characteristics of the bonded type anchorage for CFRP tendon. The selected parameters are the inner angle of the anchorage barrel, the friction between the barrel and filling material, and the elastic modulus of the filling material. The difference in the behavioral characteristics is examined for each parameter. In view of the analytic results, the shear stress developed in the CFRP tendon reduces with larger inner angle of the barrel and lower elastic modulus of the filling material. However, such combination provokes also the increase of the relative displacement of the CFRP tendon. Especially, slip failure may occur due to the lack of the confining force necessary for the anchorage due to the sudden loss of vertical force brought by the wedge force. The experimental results relative to barrel inner angles of $2^{\circ}$ and $4^{\circ}$ showed that the specimen with an angle of $2^{\circ}$ preserved its anchoring performance up to tensile failure whereas the specimen with an angle of $4^{\circ}$ failed in developing its maximum anchoring performance due to slip failure.
\end{abstract}

Keywords: CFRP Tendon; Prestressing; Anchorage; Wedge

\section{Introduction}

Fiber Reinforced Polymer (FRP) has recognized recently wider applications in the construction sector owing to its advantageous material properties compared to the conventional construction materials such as concrete or steel like its higher specific strength (strength-to-weight ratio), resistance to corrosion and convenient workability. FRP started to be used in construction as strengthening material for degraded structures and is today exploited as structural material such as in the FRP deck to replace the concrete deck or as a mean to replace corrodible materials like steel reinforcement or steel wire. Especially, efforts are being recently attempted to replace the steel wires used as tendons in prestressed concrete structures by the non-corrodible FRP [1].

Most of the FRP tendons are made of CFRP (Carbon FRP). Unlike conventional steel, CFRP is an anisotropic material with outstanding strength characteristics in the direction of the fibers but low lateral strength in the direction perpendicular to the fibers, which presents limitations for the immediate use of the traditional steel tendon anchorage. The currently commercialized or reported anchorages for FRP tendon are the wedge type, pressure type and bonded type anchorages [2,3]. The wedge type anchorage uses mechanical gearing, which provokes the concentration of stress at the front of the wedge and causes early failure of FRP. In order to overcome this problem, several researchers proposed to change the angles of the wedge and barrel or to vary locally the stiffness of the wedge [4]. The pressure type anchorage exhibits outstanding performance compared to the wedge type anchorage by determining the dimensions of the sleeve enabling to introduce the adequate pressure force necessary for the anchoring. However, it is difficult to derive the appropriate dimensions of the sleeve considering the low shear strength of FRP [5]. Both wedge type and pressure type anchorages are variants of the traditional anchorages used for steel tendons. Besides, the bonded type anchorage relies on the bond strength between FRP and the filling material without relying on the low shear strength of FRP. This type of anchorage has been proposed for the tensile test of FRP members in major standards dedicated to FRP such as ACI [6], ASTM [7] and CSA [8]. Since the bonded type anchor- 
age relies on the bond strength, it is disadvantageously longer than the wedge type or pressure type anchorages. Reference [3] reported that the length of the bonded mold should more than 50 times longer than the diameter of the tendon for FRP to reach failure. Even if the length of the anchorage can be shortened because compressive force can be expected bond force and the wedge action, the conic resin-potted anchorage obtained by processing the inner part of the steel tube mold of the bonded type anchorage into a conic shape still necessitates solutions enabling to mitigate the concentration of stress occurring at the frontal part of the filling material in the wedge similarly to the wedge type anchorage.

This paper intends to examine the behavioral characteristics of the CFRP tendon and anchorage according to the wedge action of the conic anchorage in order to manufacture the optimal conic bonded type anchorage realized by endowing a conic shape to the inner part of the steel tube mold of the bonded type anchorage for CFRP tendon. To that goal, three dimensional finite element analyses are performed on the conic anchorage. The performances of the anchorage are investigated through parametric study for further development of the bonded type anchorage for CFRP tendon. In addition, directions for the fabrication of the bonded type anchorage necessary for the effective development of the anchoring performance are proposed based upon the analysis of the results of the tests conducted on various bonded type anchorages.

\section{Analysis of Bonded Type Anchorage}

\subsection{Selection of Parameters}

As mentioned above, the conic anchorage applies the wedge force on the CFRP tendon through the wedge action generated by the inner filling material and the angle of the barrel. The vertical force produced by the wedge action can be obtained by the increase of the frictional force confining the tendon. However, an excessive vertical force produced by the wedge may provoke shear failure of the tendon similarly to the conventional wedge type anchorage as shown in Figure 1.

Besides, insufficient wedge force will generate insufficient frictional force and may result in early slip failure. Accordingly, need it to examine the factors influencing significantly the vertical force generated by the wedge action in order to secure the appropriate confining force by the conic shape. Figure 2 describes the composition of the conic bonded type anchorage for CFRP tendon together with the major influential factors. The major factors affecting the performances of the conic bonded type anchorage are the bond length, the angle of the inner filling cylinder, the coefficient of friction between the filling material and the barrel, and the elastic modulus of

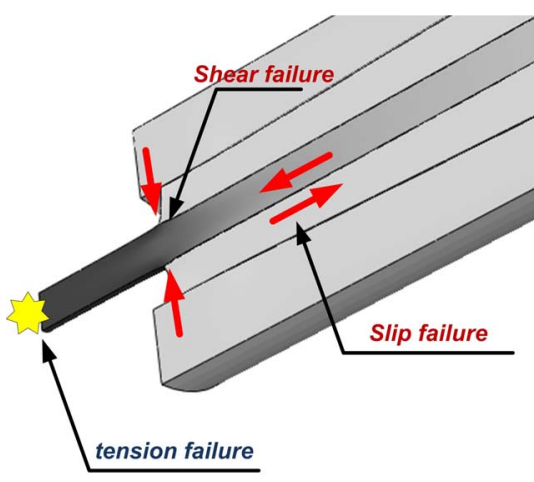

Figure 1. Failure mode of anchorage.

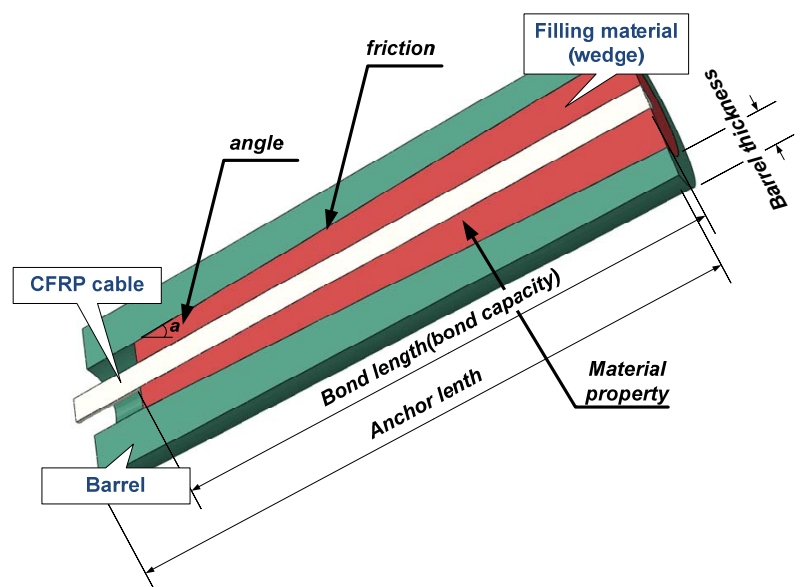

Figure 2. Composition of conic bonded type anchorage.

the filling material.

The parameters considered in this study are the coefficient of friction between the filling material and the barrel, the inner angle of inclination of the barrel, and the type of filling material (epoxy, mortar, aluminum). The designation with respect to these parameters is defined in Figure 3. In the analysis, the effects according to the change in each of the parameters is investigated with reference to an inner angle of $2^{\circ}$, a coefficient of friction of 0.5 and an elastic modulus of $42 \mathrm{GPa}$ for the inner filling material.

\subsection{Analysis Model}

The anchorage considered in the analysis is composed of the CFRP cable, the inner filling material, and the external barrel. The basic dimensions of the anchorage are presented in Figure 4. The barrel is assumed to be made of steel with an elastic modulus of $200 \mathrm{GPa}$ and a Poisson's ratio of 0.33 . The CFRP tendon developed by the Korea Institute of Construction Technology (KICT) has a nominal diameter of $5 \mathrm{~mm}$ and an elastic modulus of 200 GPa and a Poisson's ratio of 0.27 are used in the analysis. The considered anchorage is a 7-wire multi-tendon anchorage. For the convenience of analysis, the 7 tendons 


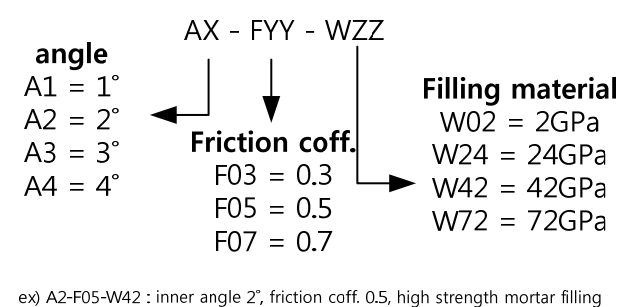

Figure 3. Designation of parameters.

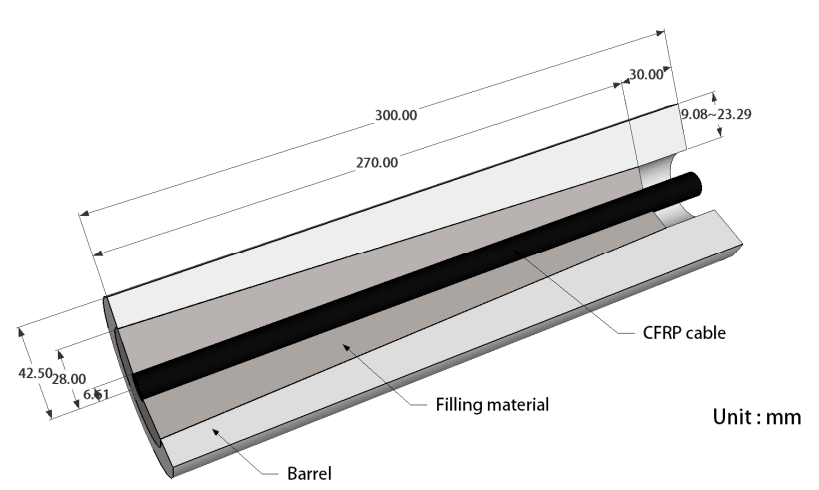

Figure 4. Dimensions of anchorage.

are modeled by converting them into a unique tendon with cross-sectional area corresponding to the nominal cross-sectional areas of the 7 tendons. In other words, the analysis does not consider the inter-layer shear between the CFRP wires. The elastic modulus of the material filling the barrel is adopted as parameter in the analysis. The elastic modulus is varied from 2 to $72 \mathrm{GPa}$ assuming low strength epoxy to aluminum.

The commercial finite element analysis software ABAQUS is used for the analysis. Three dimensional model is adopted to produce results simulating appropriately the actual behavior. A half model with reference to the center of the CFRP cable is used for the efficiency of the analysis (Figure 5). Eight-node solid elements are applied in the analysis. Since modeling is performed so that the nodes are shared by the elements, the computational time is shortened and numerical errors are reduced.

The CFRP cable and the inner filling material are assumed to be perfectly tied. Modeling is also performed by using surface-to-surface contact condition between the inner filling material and the barrel.

In the surface-to-surface contact condition, the contact stress-spacing condition in the direction perpendicular to the contact surface is assumed as hard contact so that the contact behaves as perfect bonding when the spacing between the surfaces of contact falls below a definite value and so that the surfaces of contact separate according to the stress state and spacing condition after contact. The shear friction force occurring in the direction parallel to the contact surface varies with respect to the size of the input coefficient of friction. The boundary conditions

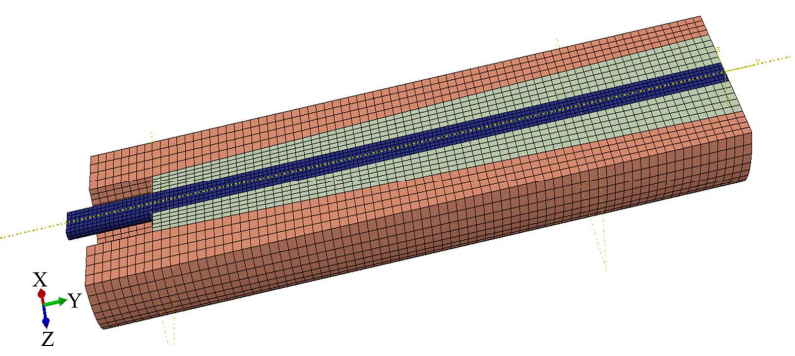

Figure 5. Finite element model of anchorage.

are shown in Figure 6. The top of the barrel (opposite to the loaded face) fixed by a nut is assigned with boundary conditions restraining the displacement and rotation and, the cut face has its displacement and rotation restrained in its out-of-plane direction.

Loading is applied as stress on the surface of the end of the CFRP tendon. A stress of $4000 \mathrm{MPa}$ corresponding to the tensile strength of the CFRP tendon is applied to evaluate the behavior of the anchorage and tendon up to the failure of the CFRP tendon.

\subsection{Analysis Results and Discussion}

Analysis was conducted for a total of 9 cases considering the coefficient of friction, the angle and the properties of the filling material as parameters and including the reference specimen A2-F05-W42. The maximum shear stress (S12) developed in the CFRP tendon and the maximum displacement $\left(D_{y}\right)$ of the tendon at its loaded end resulting from the analysis are as follows. As listed in Table 1, the largest maximum shear stress developed in the tendon occurs with the largest elastic modulus of the inner filling material and the smallest maximum shear stress is developed with the lowest elastic modulus of the filling material. The peak displacement of the tendon occurs when the elastic modulus of the filling material has the largest value and the smallest maximum displacement appears with the largest angle of the inner barrel.

1) Effect of Coefficient of Friction

Figure 7 plots the shear stress and displacement with respect to the coefficient of friction relative to the anchorage filled with high strength mortar (elastic modulus of $42 \mathrm{GPa}$ ) and inner angle of $2^{\circ}$.

The small graphs inserted in Figure 7 plot the peak values per parameter. The maximum shear stress developed in the CFRP tendon is $243.8 \mathrm{MPa}$ and $225.2 \mathrm{MPa}$ when the coefficient of friction is 0.7 and 0.3 , respectively, which shows its tendency to increase slightly with larger coefficients of friction. The analysis revealed that all the anchorages filled with high strength mortar and inner angle of $2^{\circ}$ experienced stresses lower than the shear strength of $267 \mathrm{MPa}$ of the CFRP tendon developed by KICT regardless of the coefficient of friction. 
Table 1. Maximum shear stress and maximum displacement per parameter.

\begin{tabular}{|c|c|c|c|c|c|}
\hline Parameter & $\begin{array}{c}\text { Inner angle of } \\
\text { barrel }\left(^{\circ}\right)\end{array}$ & $\begin{array}{l}\text { Coefficient of } \\
\text { friction }\end{array}$ & $\begin{array}{c}\text { Elastic modulus of filling } \\
\text { material (GPa) }\end{array}$ & $\begin{array}{c}\text { Maximum shear stress of } \\
\text { tendon }(\mathrm{MPa})\end{array}$ & $\begin{array}{l}\text { Maximum displacement of } \\
\text { tendon at loaded end }(\mathrm{mm})\end{array}$ \\
\hline A1-F05-W42 & 1.0 & 0.5 & 42 & 263.22 & -6.89 \\
\hline A2-F03-W42 & 2.0 & 0.3 & 42 & 225.17 & -4.00 \\
\hline A2-F05-W02 & 2.0 & 0.5 & 2 & 50.99 & -10.48 \\
\hline A2-F05-W24 & 2.0 & 0.5 & 23.5 & 181.29 & -4.33 \\
\hline A2-F05-W42 & 2.0 & 0.5 & 42 & 235.98 & -3.56 \\
\hline A2-F05-W72 & 2.0 & 0.5 & 72 & 291.49 & -2.98 \\
\hline A2-F07-W42 & 2.0 & 0.7 & 42 & 243.77 & -3.29 \\
\hline A3-F05-W42 & 3.0 & 0.5 & 42 & 212.15 & -2.78 \\
\hline A4-F05-W42 & 4.0 & 0.5 & 42 & 177.37 & -2.42 \\
\hline
\end{tabular}

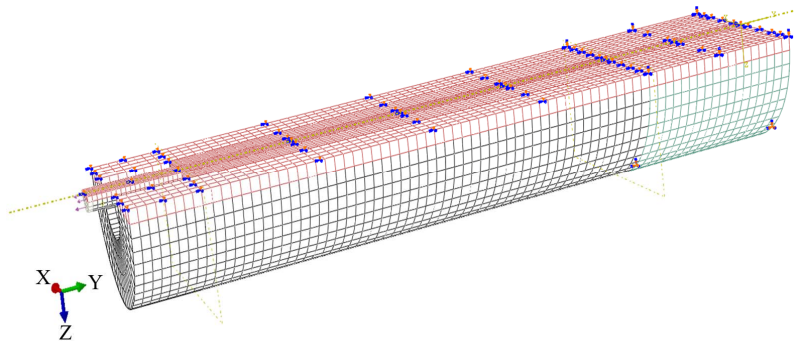

Figure 6. Boundary conditions and load conditions of analysis model.

The shear stress along the direction of the tendon remains smaller than $20 \mathrm{MPa}$ at the free end (end opposite to the loaded end) but increases suddenly from the point located $200 \mathrm{~mm}$ far away from the free end to reach a value larger than $200 \mathrm{MPa}$ at the loaded end. Such distribution of the shear stress along the tendon appears to be similar in all the anchorages regardless of the coefficient of friction. The shear stress at the loaded end becomes larger with larger coefficients of friction. The shear stress developed in the portion within $50 \mathrm{~mm}$ from the free end of the tendon appears to be larger with smaller coefficients of friction. Unlike the stress, the displacement of the tendon reduces with larger coefficients of friction. The relative displacement of the loaded end to the free end of the tendon reaches $1.07 \mathrm{~mm}$ for a coefficient of friction of 0.3 and becomes respectively 0.99 $\mathrm{mm}$ and $0.92 \mathrm{~mm}$ for the coefficients of friction of 0.5 and 0.7 . This indicates that the relative displacement experiences slight decrease with larger coefficients of friction.

2) Effect of Strength of Barrel

Figure 8 plots the shear stress and displacement of the CFRP tendon according to the inner strength of the barrel in the case of identical type of filling material and coefficient of friction.

Differently from the results related to the change in the

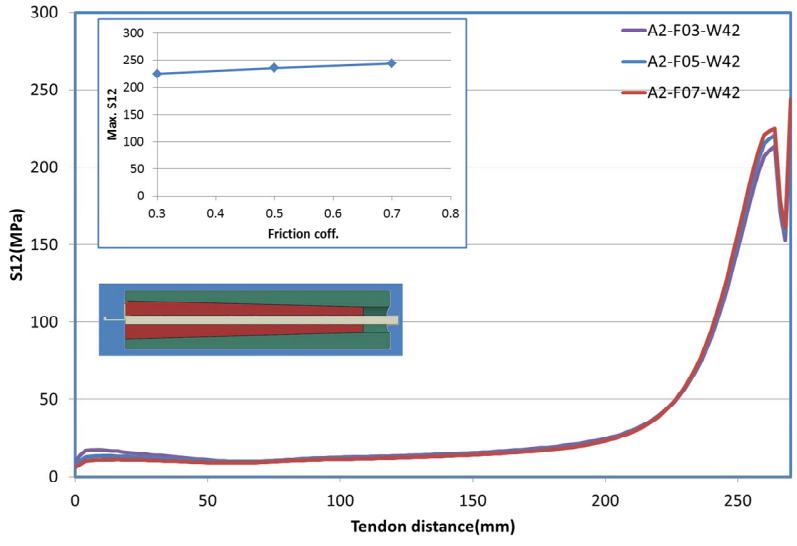

(a)

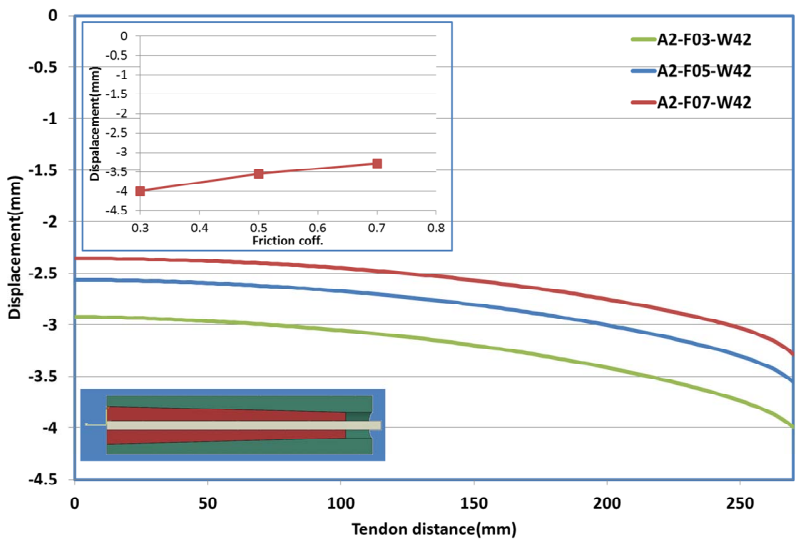

(b)

Figure 7. Shear stress and displacement of CFRP tendon according to the coefficient of friction. (a) Shear stress; (b) Displacement.

coefficient of friction, the maximum shear stress in the cable tends to decrease with larger inner angle. Especially, the shear stress along the direction of the tendon shows also relatively uniform distribution. The maximum shear stress for an inner angle of $1^{\circ}$ reaches $263.2 \mathrm{MPa}$, 


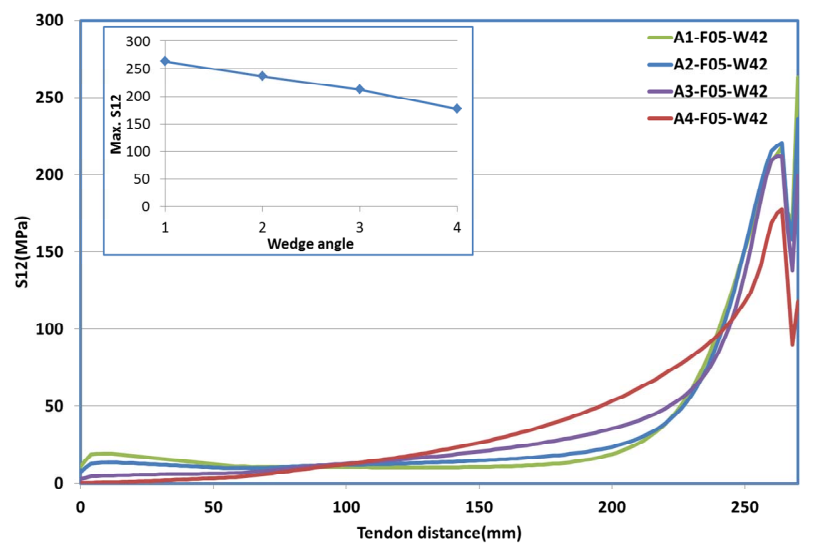

(a)

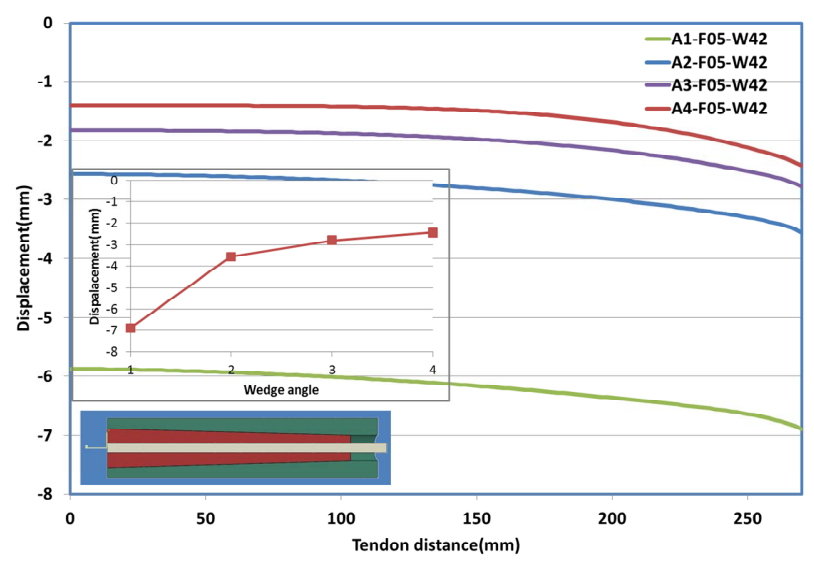

(b)

Figure 8. Shear stress and displacement of CFRP tendon according to the inner angle. (a) Shear stress; (b) Displacement.

which corresponds to $99 \%$ of the shear strength of the CFRP tendon. In the anchorage with an inner angle of $4^{\circ}$, the maximum shear stress reaches $177.4 \mathrm{MPa}$ corresponding to a reduction of approximately $33 \%$ compared to the shear stress for the inner angle of $1^{\circ}$.

As shown in Figure 8, the shear stress in the portion within about $80 \mathrm{~mm}$ from the free end of the CFRP tendon decreases with smaller inner angle and the shear stress in the portion from $80 \mathrm{~mm}$ and $230 \mathrm{~mm}$ from the free end increases with smaller inner angle. This means that the shear stress concentrates at the loaded end of the tendon as much as the inner angle is small and tends to distribute relatively along the length of the tendon with larger inner angle. Such stress distribution can be attributed to the reduction of the force produced by the wedge action consecutive to the increase of the inner angle and to the fact that the anchorage by bonding governs the performance.

The relative displacement between the free end and loaded end of the tendon shows practically no change according to the variation of the inner angle. The relative displacement for an inner angle of $1^{\circ}$ reaches $1.015 \mathrm{~mm}$ and reaches $1.020 \mathrm{~mm}$ for an inner angle of $4^{\circ}$ representing merely a difference of $0.5 \%$ between these two angles. However, the displacement provoked by the wedge sliding appears to increase with smaller inner angle. Especially, the sliding displacement of the tendon for the inner angle of $1^{\circ}$ is larger by about 4 times compared to that corresponding to the inner angle of $4^{\circ}$.

3) Effect of the Properties of the Filling Material

Figure 9 plots the shear stress and displacement of the cable according to the properties of the filling material.

As shown in Figure 9, the physical properties of the filling material inside the conic anchorage have the largest effect on the maximum shear stress of the CFRP tendon compared to the coefficient of friction and inner angle. The maximum shear stress occurring in the tendon according to the elastic modulus of the inner filling material is seen to vary from 51.0 $\mathrm{MPa}$ and $291.5 \mathrm{MPa}$. When using epoxy, the filling material with very low elastic modulus, the maximum shear stress in the CFRP tendon reaches 51.0 MPa corresponding to $19 \%$ of the shear strength of the CFRP tendon and shows even distribution ranging from $35 \mathrm{MPa}$ to $51 \mathrm{MPa}$ along the

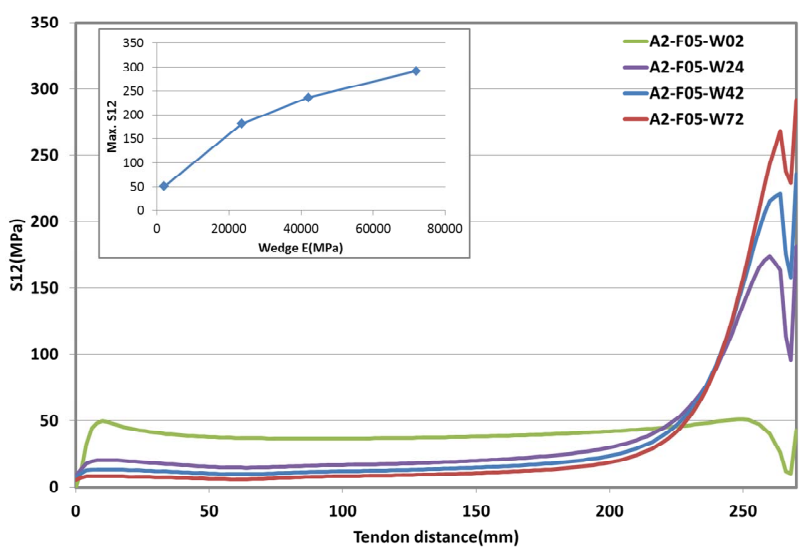

(a)

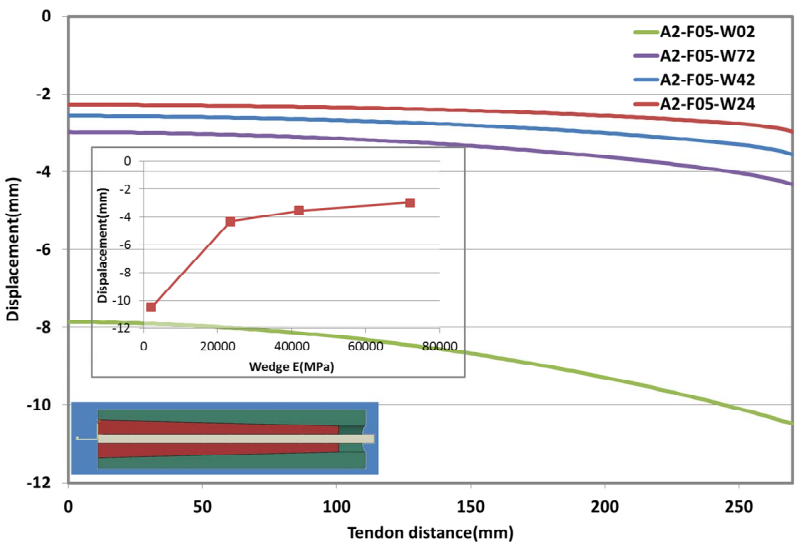

(b)

Figure 9. Shear stress and displacement of CFRP tendon according to the properties of the filling material. (a) Shear stress; (b) Displacement. 
tendon. The maximum shear stress in the CFRP tendon experiences also sudden increase with larger elastic modulus of the filling material. In the anchorage assumed to be filled with aluminum, the maximum shear stress reaches 291.5 MPa resulting to the shear failure of the tendon prior to the tensile failure of the CFRP tendon. Accordingly, the physical properties of the filling material appear to have effect on the mitigation of the concentration of the shear stress. Especially, the use of a filling material with low elastic modulus is seen to be effective in reducing the significant shear stress occurring at the loaded end of the tendon. Based upon this observation, Figure 10 illustrates the solutions proposed for the anchorage for CFRP tendon by filling the anchorage by a low elastic modulus material in the portion featured by the concentration of stress [9].

In Figure 9(b) plotting the displacement of the CFRP tendon with respect to the physical properties of the filling material, it can be observed that comparatively larger difference in the relative displacement between the free end and loaded end of the tendon is obtained than in the analysis results corresponding to the variation of the coefficient of friction or inner angle. The sliding of the inner filling material becomes significant with lower elastic modulus of the filling material. The relative displacement between the free end and loaded end of the CFRP tendon also shows a tendency to increase in such case. For the parameter A2-F05-W02 exhibiting the lowest elastic modulus of the filling material, the sliding of the free end of the CFRP tendon reaches $7.86 \mathrm{~mm}$ and the relative displacement between the free end and loaded end of the tendon is $2.62 \mathrm{~mm}$. For the parameter A2-F05-W72 exhibiting the highest elastic modulus of the filling material, the sliding of the free end of the CFRP tendon reaches $2.98 \mathrm{~mm}$ and the relative displacement between the ends of the tendon is $1.35 \mathrm{~mm}$.

\section{Test and Verification of the Anchorage}

\subsection{Material Test of CFRP Tendon}

The CFRP tendon considered in this study is made of 5 $\mathrm{mm}$-diameter steel wires that have not received separate surface treatment. Therefore, tensile test was conducted in compliance with the testing method of [1] proposed by modifying the CSA testing method. In order to improve the bond performance of the non-surface treated tendons, the cross-section of the tendon was quadrisected longitudinally to increase the bond area and alumina oxide coating was applied on the surface to secure sufficient bond performance between the filling material and the tendon as shown in Figure 11. Figure 12 illustrates the strengthening of the extremity by using small quantities of fiber to prevent longitudinal splitting.

The so-treated CFRP tendon was then aligned in the steel tube as shown in Figure 13 and the specimen was filled with non-shrinkage mortar as applied in the reference specimen in the analysis. The tensile test was performed after completion of more than 7 days of curing for the mortar to develop sufficient strength. Figure 14 presents the compressive strength per age of the mortar used as filling material. A water-to-mortar ratio of $16 \%$ was adopted considering the workability of mortar during filling.

A UTM (Universal Testing Machine) with capacity of $980 \mathrm{kN}$ was used for the tensile test of the CFRP tendon. Loading was applied through displacement control at speed of $0.0835 \mathrm{~mm} / \mathrm{sec}$. Tensile test was conducted on a total of 10 tensile specimens. All the specimens failed typically through tensile failure of FRP (Figure 15). All the specimens exhibited strength higher than the nominal strength of $4000 \mathrm{MPa}$ specified by the manufacturer. The tensile test results of each specimen are listed in Table 2.
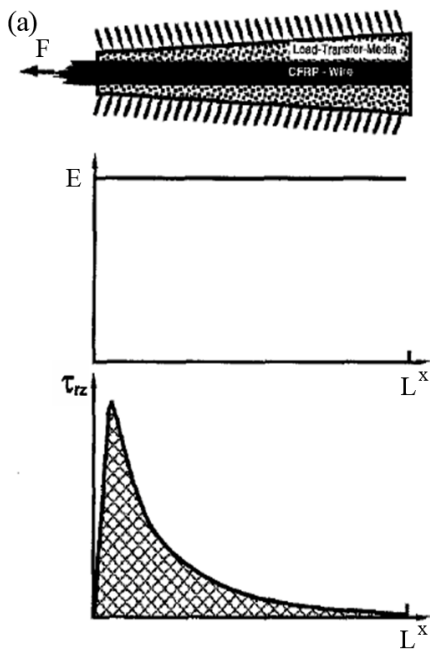
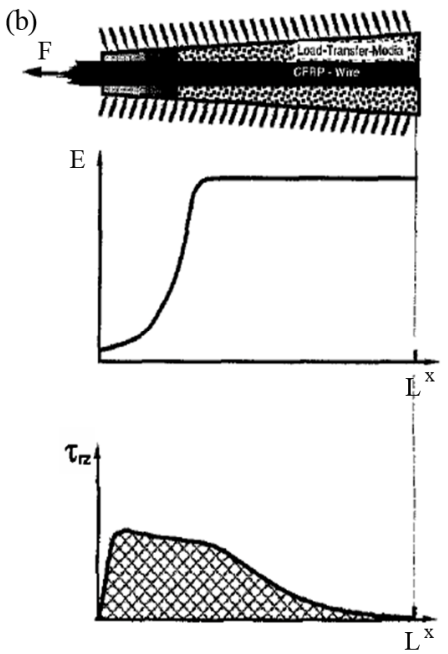
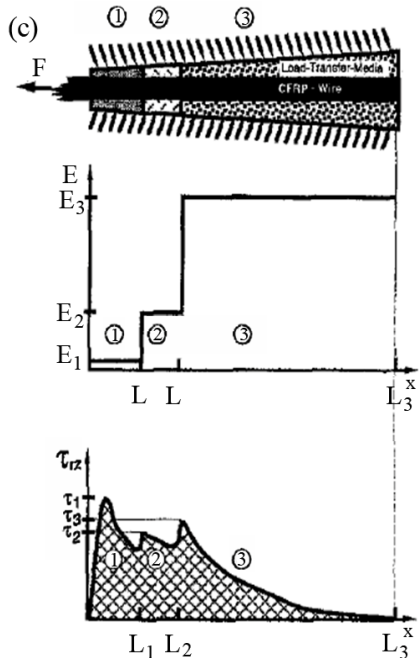

Figure 10. Solutions for the mitigation of shear stress. 


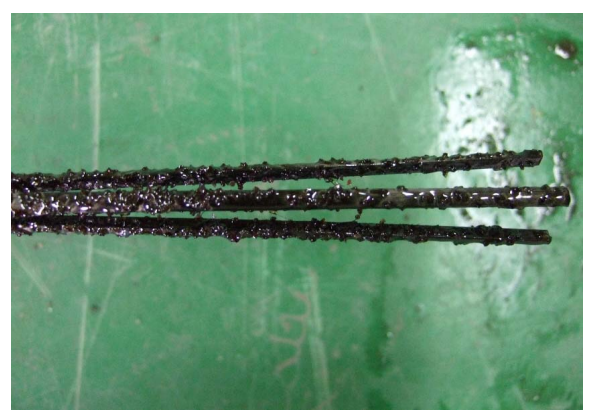

Figure 11. Quadrisected and oxide coated extremity of CFRP tendon.

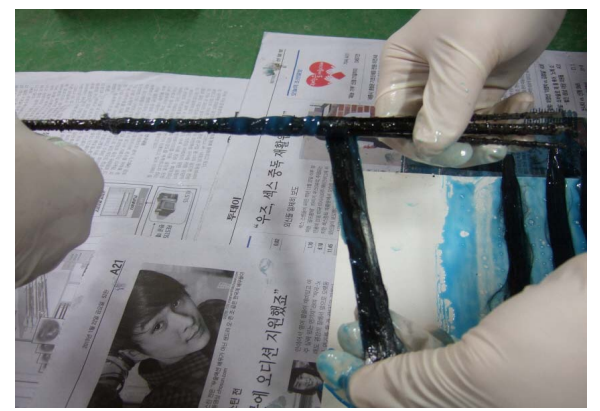

Figure 12. Fiber reinforcement of tendon end.

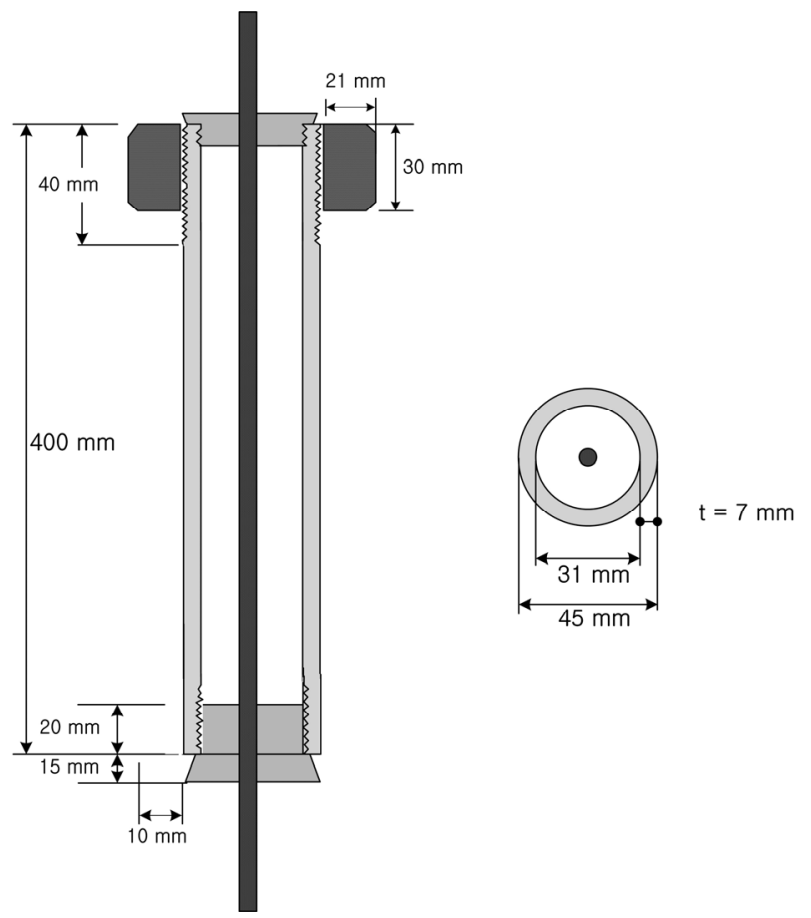

Figure 13. Specification of steel molds.

\subsection{Test of 7-CFRP Wire Anchorage}

1) Preliminary Test

Prior to the test on the bonded type conic anchorage addressed in the analysis model of this study, preliminary test was conducted on the anchorage with 7 multi-ten-

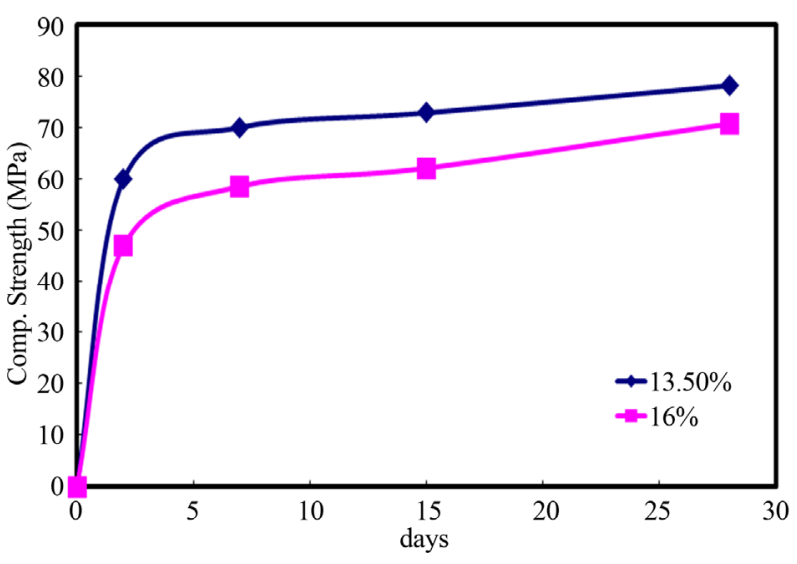

Figure 14. Compressive strength of mortar.
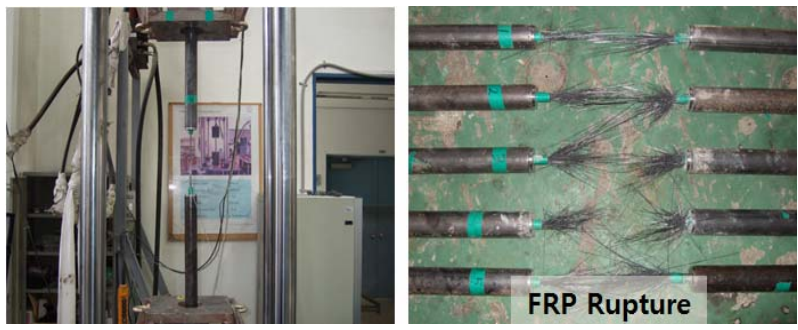

Figure 15. View of tensile test and failure pattern.

dons to verify the anchoring performance of the bonded type anchorage (Table 3). In the preliminary test, tensile test is carried out on a specimen with the extremity of each individual tendon processed like in the tensile test of the single tendon and a specimen in which the tendons are disposed with large spacing and without particular treatment of the extremities. Here also, both specimens have their surface coated with alumina oxide so as to increase the surface bond strength.

The test was conducted using the same method as the tensile test of the CFRP tendon. The final test results are arranged in Table 4. The simply bonded preliminary test specimen II failed through slip in the individual tendons at loading of $319.81 \mathrm{kN}$ corresponding to $58 \%$ of the nominal strength of the CFRP tendon.

Figure 16 plots the load-displacement curve measured on the preliminary test specimen I of which the bond surface was enlarged. It can be seen that slip occurred locally around $310 \mathrm{kN}$ and that the final slip failure (Figure 17) occurred at $516.05 \mathrm{kN}$ corresponding to $94 \%$ of the nominal tensile strength of the CFRP tendon.

2) Preliminary Test

The simple bonded type anchorage failed to develop $100 \%$ of its anchoring performance by slip. The test on the conic bonded type anchorage demonstrated the effective improvement of the bond performance by the wedge action. The anchorage specimens were manufactured to present inner angles of $2^{\circ}$ and $4^{\circ}$ in the barrel as considered in the analysis. Test was also additionally conducted 
Table 2. Maximum shear stress and maximum displacement per parameter.

\begin{tabular}{cccccc}
\hline Specimen & Maximum load $(\mathrm{kN})$ & Tensile strength $(\mathrm{MPa})$ & Maximum displacement $(\mathrm{mm})$ & Strain $\left(10^{-6}\right)$ & Elastic modulus $(\mathrm{GPa})$ \\
\hline 1 & 86.77 & 4419 & 20.20 & - & 231.59 \\
2 & 89.12 & 4538 & 20.10 & 17,748 & 242.32 \\
3 & 90.25 & 4596 & 21.79 & 18,703 & 237.18 \\
4 & 87.82 & 4472 & 21.26 & 17,345 & 238.28 \\
5 & 88.23 & 4493 & 20.35 & - & 239.15 \\
6 & 81.59 & 4155 & 16.76 & 15,258 & 236.14 \\
7 & 89.23 & 4544 & 17.05 & 17,133 & 239.59 \\
8 & 84.96 & 4327 & 17.62 & 15,806 & 230.35 \\
9 & 86.85 & 4423 & 16.57 & 16,957 & 240.57 \\
10 & 82.10 & 4181 & 15.61 & 16,608 & 235.23
\end{tabular}

Table 3. Preliminary test variables for 7 -wire.

\begin{tabular}{cccc}
\hline \multirow{2}{*}{$\begin{array}{c}\text { Preliminary } \\
\text { test }\end{array}$} & \multicolumn{2}{c}{ Dimensions of steel tube $(\mathrm{mm})$} & \multirow{2}{*}{ Treatment of tendon end } \\
\cline { 2 - 3 } & Outer diameter & Thickness & \\
\hline I & 76.3 & 7 & Enlargement of bond area \\
II & 76.3 & 7 & Simple bond \\
\hline
\end{tabular}

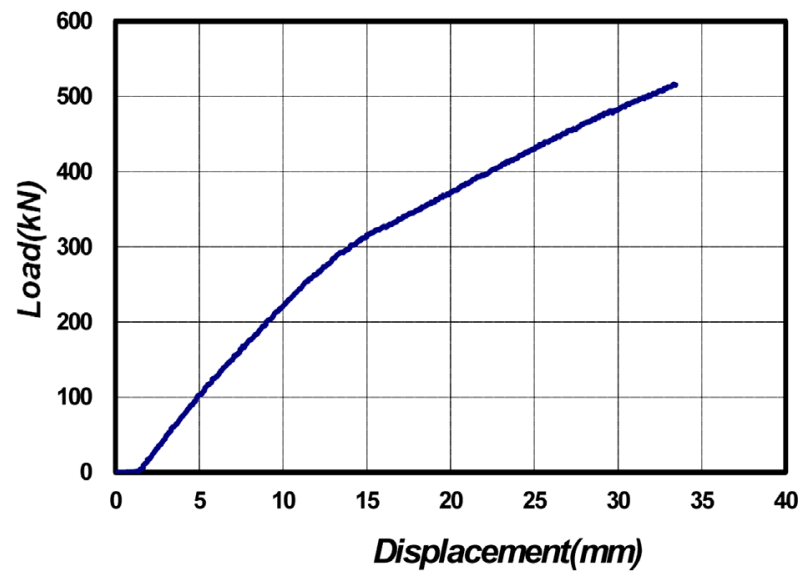

Figure 16. Load-displacement curve of preliminary test specimen $I$.

on an anchorage specimen with inner barrel angle of $0^{\circ}$ for further comparison with the simple bonded type anchorage. The major dimensions of the anchorages are presented in Figure 18. The anchorages were fabricated to be supported by means of a nut identically to the analysis model. The treatment of the extremity of the CFRP tendons and the test were carried out identically to the methods adopted for preliminary test specimen I.

The final failure patterns of the 7-wire anchorages are
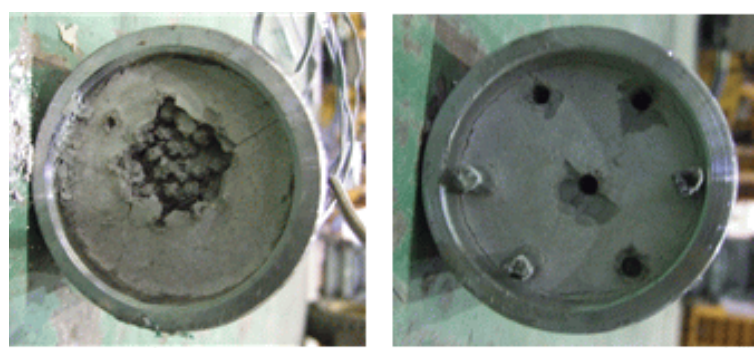

Figure 17. Slip failure pattern at the extremity of the preliminary test specimens. (a) Specimen I; (b) Specimen II.

illustrated in Figure 19. Figure 20 plots the corresponding load-displacement curves.

The simple bonded type anchorage with inner angle of $0^{\circ}$ (M7-0) experienced local slip around $350 \mathrm{kN}$ similarly to the preliminary test but final failure occurred at load of $587.19 \mathrm{kN}$ through the breakage of the CFRP tendon. Unlike specimen M7-0, the specimen with inner angle of $2^{\circ}$ (M7-2) preserved a linear behavior until its final failure at $599.71 \mathrm{kN}$ through rupture of the CFRP tendon. The absence of slip in M7-2 can be explained by the confinement of the tendon by the lateral force produced by the wedge action. The specimen with inner angle of $4^{\circ}$ (M7-4) experienced slip at $342.73 \mathrm{kN}$ and final failure at $481.29 \mathrm{kN}$. As seen in the analysis results, the lateral force generated by wedge action in specimen M7-4 appears to be insufficient in anchoring the tendon. Especially, it seems also that the inner space of the barrel narrowed by the inner angle was insufficient to secure the density of the filling mortar. As shown in Figure 19(c), the core wire located at the center of specimen M7-4 was practically not anchored and resulted in the failure of the remaining 6 wires around the peak tensile load of $471 \mathrm{kN}$. 

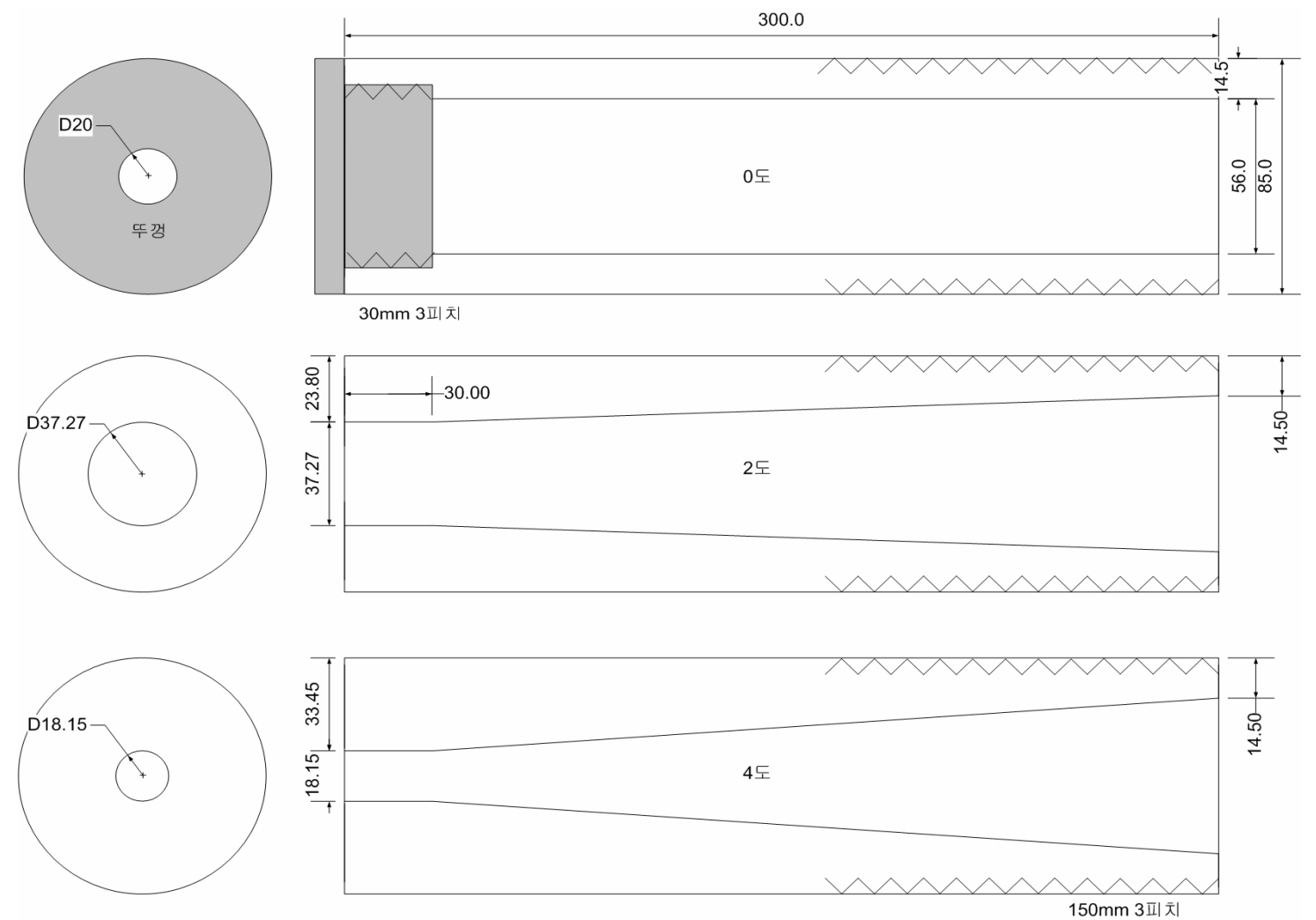

Figure 18. Dimensions and shapes of 7-wire anchorage specimens.

Table 4. Results of preliminary test of 7-wire.

\begin{tabular}{cccccc}
\hline Specimen & Maximum load $(\mathrm{kN})$ & Tensile strength of CFRP $(\mathrm{MPa})$ & Maximum displacement $(\mathrm{mm})$ & Strain $\left(10^{-6}\right)$ & Elastic modulus $(\mathrm{GPa})$ \\
\hline Preliminary specimen I & 516.05 & 3755 & 33.33 & 15,925 & 232 \\
Preliminary specimen II & 319.81 & 2326 & 12.92 & 10,773 & 221 \\
\hline
\end{tabular}

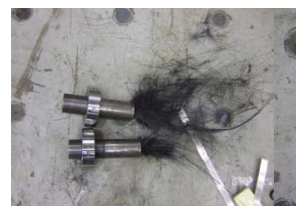

(a)

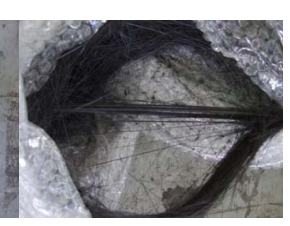

(c)

Figure 19. Failure patterns of 7-wire anchorage. (a) M7-0; (b) M7-2; (c) M7-4.

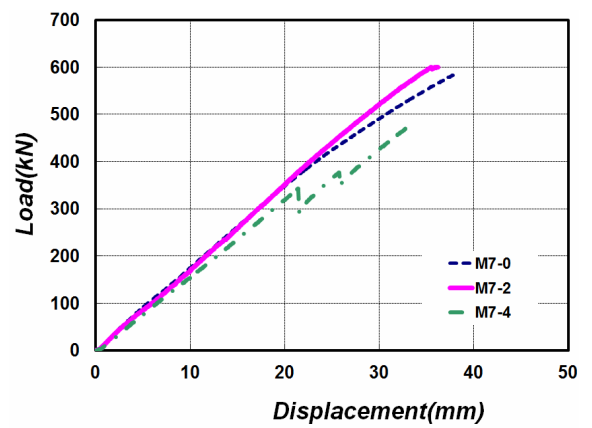

Figure 20. Load-displacement curve of 7-wire anchorage.

\section{Conclusion}

This study intended to investigate the behavioral characteristics of the bonded type anchorage for CFRP tendon. To that goal, finite element analysis was conducted on the parameters affecting the anchoring performance and the shear stress and displacement occurring in the CFRP tendon were analyzed. The analysis results revealed that the shear stress developed in the CFRP tendon decreased with larger inner angle of the barrel and lower elastic modulus of the filling material. However, this combination resulted also in the sudden loss of the vertical force generated by the wedge force leading to the lack of confining force necessary for the anchoring and subsequently to the occurrence of slip failure. In the case of an inner barrel angle of $1^{\circ}$, it appeared that the shear stress close to the shear strength of CFRP tendon was developed. In the case of an elastic modulus of $72 \mathrm{GPa}$ for the filling material, shear stress larger than the shear strength developed resulting in the occurrence of shear failure in the anchorage prior to the tensile failure of the tendon. 
Based upon these results, the optimal bonded type anchorage appeared to be the anchorage with inner barrel angle of $2^{\circ}$ and is filled with mortar. Therefore, tests were carried out on specimens with inner barrel angles of $0^{\circ}, 2^{\circ}$ and $4^{\circ}$ to verify the analysis results. The experimental results also showed that the simple bonded type anchorage specimens with inner barrel angles of $0^{\circ}$ and $4^{\circ}$ failed in developing their maximum performance due to slip failure whereas the specimen with inner barrel angle of $2^{\circ}$ was able to exhibit its anchoring performance up to the tensile failure of the tendon, which confirmed the analysis results.

\section{Acknowledgements}

This research was supported by grant from Strategic Research Project (Development of Bridge Strengthening Method using Prestressed FRP Composites) funded by Korea Institute of Construction Technology.

\section{REFERENCES}

[1] W. T. Jung and J. S. Park, "An Experimental Study on Tensile Characteristic for CFRP Cable without Surface Treatments," Procedia Engineering, Vol. 14, 2011, pp. 1518-1523.

http://dx.doi.org/10.1016/j.proeng.2011.07.191

[2] A. Nanni, C. E. Bakis, P. E. O'Niel and T. O. Dixon, "Performance of FRP Tendon-Anchor Systems for Prestressed Concrete Structures," PCI Journal, Vol. 41, No.
1, 1996, pp. 34-43.

[3] J. A. Pincheira and J. P. Woyak, "Anchorage of Carbon Fiber Reinforced Polymer (CFRP) Tendons Using ColdSwaged Sleeves," PCI Journal, Vol. 46, No. 6, 2001, pp. 100-111.

[4] A. Al-Mayah, K. A. Soudki and A. Plumtree, "Experimental and Analytical Investigation of a Stainless Steel Anchorage for CFRP Prestressing Tendons," PCI Journal, Vol. 46, No. 2, 2001, pp. 88-100.

[5] E. A. Shaheen, "Carbon Fibre Reinforced Reactive Powder Concrete (CFRRPC) Anchorage System," Ph.D. Thesis, University of Calgary, Calgary, 2004.

[6] ACI Committee 440, "Guide Test Methods for Fiber-Reinforced Polymers (FRPs) for Reinforcing or Strengthening Concrete Structures," ACI 440.3R-04, 2004.

[7] ASTM D 3916-08, "Standard Test Method for Tensile Properties of Pultruded Glass-Fiber-Reinforced Plastic Rod," 2008.

[8] Canadian Standard Association (CSA), "CSA Standard S806-02, Design and Construction of Building Components with Fiber-Reinforced Polymers," 2002.

[9] U. Meier and M. Farshad, "Connecting High-Performance Carbon-Fibre-Reinforced Polymer Cables of Suspension and Cable-Stayed Bridges through the Use of Gradient Materials," Journal of Computer-Aided Materials Design, Vol. 3, No. 1-3, 1996, pp. 379-384. http://dx.doi.org/10.1007/BF01185676 